DE

M E D I C I N A

T R O P I C A L

$\mathrm{DE}$

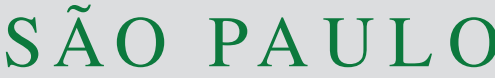

JOURNAL OF THE SÃO PAULO INSTITUTE OF TROPICAL MEDICINE

${ }^{1}$ Universidade de São Paulo, Faculdade de Medicina, Hospital das Clínicas, Subcomissão de Controle de Infecção Hospitalar, São Paulo, São Paulo, Brazil

2Universidade de São Paulo, Faculdade de Medicina, Hospital das Clínicas, Divisão de Laboratório Clínico, São Paulo, São Paulo, Brazil

${ }^{3}$ Universidade de São Paulo, Instituto de Medicina Tropical de São Paulo, Laboratório de Investigação Médica (LIM) 54, São Paulo, São Paulo, Brazil

${ }^{4}$ Universidade de São Paulo, Faculdade de Medicina, Departamento de Moléstias Infecciosas e Parasitárias, São Paulo, São Paulo, Brazil

Correspondence to: Icaro Boszczowski Universidade de São Paulo, Faculdade de Medicina, Hospital das Clínicas, Subcomissão de Controle de Infecção Hospitalar, Av. Dr. Enéas de Carvalho Aguiar, 255, Cerqueira César, CEP 05403000, São Paulo, SP, Brazil

Tel: +55 11 2661-6444

E-mail: icaro.b@hc.fm.usp.br

Received: 24 September 2018

Accepted: 10 January 2019

\section{Multidrug-resistant Klebsiella pneumoniae: genetic diversity, mechanisms of resistance to polymyxins and clinical outcomes in a tertiary teaching hospital in Brazil}

\author{
Icaro Boszczowski ${ }^{\circledR 1}$, Matias Chiarastelli Salomão ${ }^{\circledR 1}$, Maria Luísa Moura1, \\ Maristela Pinheiro Freire ${ }^{1}$, Thais Guimarães ${ }^{1}$, Ana Paula Cury², Flávia Rossi ${ }^{2}$, \\ Camila Fonseca Rizek ${ }^{3}$, Roberta Cristina Ruedas Martins ${ }^{3}$, Silvia Figueiredo \\ Costa $^{3,4}$
}

\section{ABSTRACT}

Increased resistance to polymyxin in Klebsiella pneumoniae (ColRKP) has been observed. Molecular epidemiology, as well as the clinical impact of these difficult to treat pathogens need to be better characterized. We present the clinical outcomes of 28 patients infected by ColRKP in a tertiary hospital. Isolates with MIC $>2$ by Vitek 2 were confirmed by the microdilution broth test. Polymerase chain reaction (PCR) was performed for $b l a_{\mathrm{KPC}}, b l a_{\mathrm{NDM}}, b l a_{\mathrm{OXA}-48}$ and $b l a_{\text {mcr-1 }}$ genes in the isolates, and Whole Genome Sequencing (WGS) was performed in six isolates. Seventeen $(61 \%)$ patients were female and the mean age was 50 years old. In-hospital and 30-day mortality were 64\% (18/28) and 53\% (15/28), respectively. Central line-associated bloodstream infection in addition to bacteremia episodes due to other sources were the most frequent (61\%). Mean APACHE and Charlson comorbidity index were 16 and 5, respectively. Twenty patients (71\%) received at least one active drug and ten $(35 \%)$ received two drugs: tigecycline 46\% (13/28); amikacin 21\% (6/28) and fosfomycin 3\% (1 case). Twenty-six out of 28 tested cases were positive for bla ${ }_{\mathrm{KPC}}$ Eight different clusters were identified. Four STs were detected (ST11, ST23, ST340, and ST437). Mutations on $p m r A$, arnB, udg, and yciM genes were present in all six isolates submitted to WGS; lpxMand $m g r B$ mutations were also detected in all but one isolate. In conclusion, we observed resistance to polymyxin in severely ill patients mostly from intensive care units and/or immunosuppressed patients with high mortality rates in whom a diversity of ColRKP clusters was identified and might indicate selective pressure.

KEYWORDS: Colistin resistance. Hospital epidemiology. Antibiotic therapy. Genome sequencing. Polymyxins.

\section{INTRODUCTION}

As in other parts of the world, carbapenem-resistant Klebsiella pneumoniae (CRKP) has established in Brazil as a major public health problem in the last decade ${ }^{1-3}$. Infections caused by CRKP most frequently occur in severely ill patients and mortality rates are usually as high as $40 \%$ to $70 \%{ }^{4}$. Polymyxins (colistin and polymyxin B) remain as one of the last options for severe infections caused by carbapenem-resistant (CR) Enterobacteraceae and other CR Gram-negative bacteria. As a consequence, we have seen an increased use of polymyxins in our country. Data from the Health State Department in Sao Paulo, Brazil, revealed an increase in the use of these drugs (data not published) from 2008 to 2015. We have used colistin empirically in intensive care units in our hospital for the treatment of severe cases 
due to our marked high incidence rates of infections caused by CRKP. Concomitantly, we have experienced in the last years the emergence of colistin-resistant $K$. pneumoniae $(\text { ColRKP })^{5,6}$. Resistance to polymyxins has been reported in many parts of the world and several mechanisms have been identified ${ }^{7}$. Resistance to other antimicrobial classes like quinolones, aminoglycosides and all beta-lactams usually accompany resistence to colistin. The breakpoints for resistance to colistin, as well as the best approach to test it in the clinical laboratory is still a matter of debate and due to the extremely limited options for the treatment of this agent, we face a very challenging task to diagnose and treat patients especially in the intensive care setting. Furthermore, the understanding of resistance mechanisms for ColRKP is currently in progress. Our aim was to describe 28 clinical cases of infection caused by ColRKP $K$. pneumonia and their clinical outcomes, as well as the molecular characterization of the isolates regarding the resistance to colistin and the polymyxins-resistance genes harbored by the isolates.

\section{METHODS}

We describe a case series of 28 patients older than 18 years old identified as presenting a bloodstream and/ or sterile site acquired infection caused by ColRKP at the Hospital das Clinicas, a 1,000 bed major teaching hospital affiliated to the University of Sao Paulo, Brazil, from December 2010 to October 2013. All cases were retrieved from the Hospital Infection Control Department database. Whenever there was a multiple culture diagnosis, we have only considered the first one. Concomitant infections, defined as those occurring seven days before or after the ColRKP diagnosis, were excluded. The primary outcome was 30-day mortality elapsed from the day of the ColRKP laboratory diagnosis. Associated demographic data and comorbidities were retrieved from medical charts, as well as information on antimicrobial therapy and in-hospital mortality. Therapy with active drugs was defined as receiving, after diagnosis, an antimicrobial with a minimal inhibitory concentration (MIC) within the susceptibility range, as described by the $\mathrm{CLSI}^{8}$. Patient's illness severity was scored by APACHE II and comorbidities by Charlson score.

\section{Microbiology}

The identification and the susceptibility test were first performed by routine Vitek 2 (bioMérieux ${ }^{\circledR}$ ) automated method and further confirmed by the broth microdilution test. On a routine basis, every single isolate that presented with a colistin MIC $>2 \mu \mathrm{g} / \mathrm{mL}$ were re-tested by the
E-test and confirmed by the disk-diffusion method. We further compared Vitek 2 and the broth microdilution test. Susceptibility breakpoints were those of the Clinical Standards Laboratory Institutes (CLSI) ${ }^{8}$. The Food and Drug Administration (FDA) breakpoint for Enterobacteriaceae was used specifically to test tigecycline ${ }^{9}$. The Software Whonet ${ }^{\circledR}$ was used to distribute MIC50 and MIC90 based on broth microdilution test.

\section{Molecular biology}

Polymerase chain reaction (PCR) and pulsed field gel electrophoresis (PFGE)

Firstly, the routine laboratory performed real time PCR searching for the genes $b l a_{\mathrm{KPC}}, b l a_{\mathrm{NDM}}$ and $b l a_{\mathrm{OXA}-48}$ in all isolates using the BD Max platform (BD Diagnostics, Sparks, MD $)^{9}$. After that, in the research laboratory, $m c r-1$ and $b l a_{\mathrm{NDM}}$ genes were searched by conventional PCR in 26 isolates, using the primers NDMup168 5'-GAATGTCTGGCAGCACACTT and NDMdw647 - 5' -TTGGCCTTGCTGTCCTTGAT-3' for bla $a_{\mathrm{NDM}}$; CLR5-F-5' -CGGTCAGTCCGTTTGTTC-3' and CLR5-R - 5' -CTTGGTCGGTCTGTAGGG-3' for $m c r-1^{10}$. In each reaction, strains previously identified in our hospital, harboring the genes (confirmed by Sanger's sequencing), were used as positive controls. Three negative controls were used: an initial and a final control during the PCR master mix preparation and sterilized water instead of the primers and another negative control using only sterilized water. The isolates were submitted to PFGE using the $\mathrm{X} b a \mathrm{I}$ enzyme and restriction fragments were obtained by separation using a CHEF DRIII system (Bio-Rad, Hercules, California, USA). Patterns were interpreted according to the Bionumerics software, version 7.1 (Applied-Maths, Sint-Martens-Latem, Belgium).

\section{Whole Genome Sequencing (WGS)}

We performed WGS in six isolates from three different clusters, randomly selected corresponding to A, $\mathrm{D}$ and $\mathrm{E}$ (Figure 1) and all of them were recovered from blood. Total DNA extraction was performed with Illustra bacteria genomicPrep Mini Spin Kit (GE Healthcare Life Sciences) and DNA quality verified using the NanoDrop spectrophotometer (Thermo Scientific, Delaware, USA).

The DNA concentration was checked using the Qubit ${ }^{\circledR}$ fluorometer (Thermo Scientific, Delaware, USA) and integrity on $1.5 \%$ agarose gel. The whole genome of the isolates and the libraries were sequenced by MiSeq IlluminaTM methodology and prepared with the 


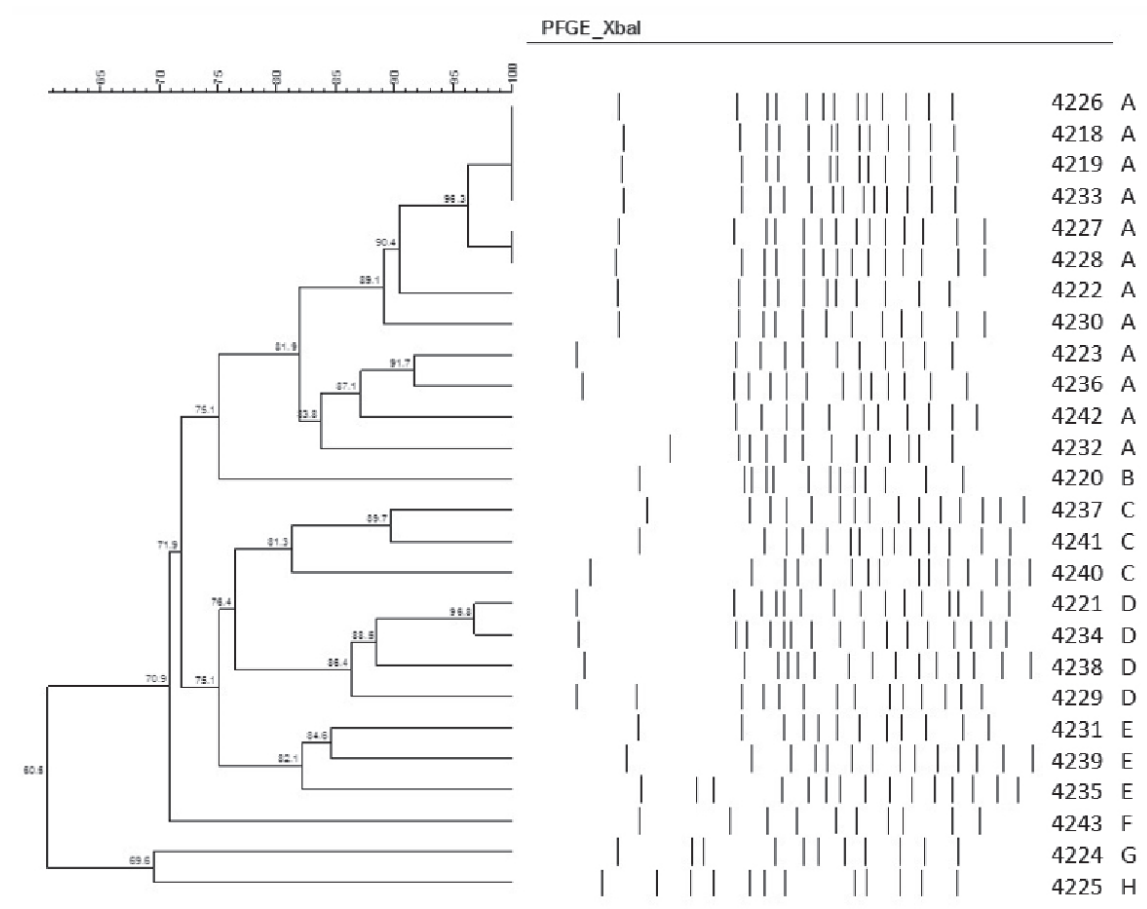

Figure 1 - Dendrogram of 28 strains of colistin-resistant Klebsiella pneumoniae. The four numbers refer to the identification of patients and letters $\mathrm{A}$ to $\mathrm{H}$ refer to the clusters.

commercial kit Nextera XT IlluminaTM according to the manufacturer's instructions. The quality control of the library was evaluated in the Tape Station System (Agilent). Paired reading segments (paired end reads) with over 500 base pairs were processed on the IlluminaTM MiSeq sequencing platform.

FastQC v programs. 0.11.3 and Trimmomatic v. 0:33 were used to evaluate the quality of the files generated by sequencing. The genome assembly was performed using the Velvet Optimiser v program. 2.2.5, and the contigs were ordered by Abacas v. 1.3.1 using the reference strain K. pneumoniae MGH78578 whose genome is available on the website of the National Center for Biotechnology Information ${ }^{11}$. The genome was annotated with the Prokka v. 1:11. using a custom Klebsiella reference library ${ }^{12}$. The sequence type (ST) was checked by the MLST finder tool (Multilocus Sequence Typing) ${ }^{13}$. Genes related to resistance were searched with the Artemis 16.0.0 program and by the ResFinder v2.1 ${ }^{14}$. Single Nucleotide Polymorphisms (SNPs) were identified by mapping the sequencing reads of the isolates using t the K. pneumoniae MGH78578 as the reference, using BWA, SAM tools and Genome Analysis Toolkit (GATK). All SNPs were manually checked.

Restriction fragments were obtained by separation using a CHEF DRIII system (Bio-Rad, Hercules, California, USA). Patterns were interpreted according to the Bionumerics version 7.1 (Applied-Maths, Sint-MartensLatem, Belgium).

\section{Statistics}

The Chi-square test was used for categorical variables and the Fisher test when adequate. Mann-Whitney was used for continuous variables. Data were analyzed using the EPIINFO 7.0.

\section{RESULTS}

Twenty-eight patients were included, and their clinical characteristics are summarized in Table 1. Seventeen $(61 \%)$ were female and their mean age was 50 years old (range 20-73). Crude in-hospital and 30-day mortality were $64 \%(18 / 28)$ and $53 \%(15 / 28)$, respectively. Sixteen patients $(57 \%)$ were in intensive care units (surgical, liver transplant recipients, hematopoietic stem cell transplant recipients and infectious diseases units) and twelve $(43 \%)$ were in different wards, mostly surgical units. The main comorbidities were chronic liver disease (14\%), hematopoietic stem cell transplantation (HSCT) (7\%), solid tumors $(32 \%)$, hematological malignancy other than HSCT (11\%). Sources of infection were intra-abdominal $(n=15,53 \%)$, central line associated bloodstream infection (CLABSI) $(\mathrm{n}=11,39 \%)$ and two others $(3 \%)$ that were abdominal wall abscesses. Thirteen patients (43\%) were exposed to polymyxins (twelve to colistin and one to polymyxin B) prior to diagnosis of infection caused by ColRKp. All bacteremia episodes (CLABSI + secondary 
Table 1 - Clinical data of 28 patients with Colistin-resistant Klebsiella pneumoniae infection.

\begin{tabular}{|c|c|c|c|c|c|c|c|c|}
\hline \multirow[b]{2}{*}{$\mathrm{Pt}$} & \multirow[b]{2}{*}{ Sex } & \multirow[b]{2}{*}{ Age } & \multirow[b]{2}{*}{ Site of infection } & \multirow{2}{*}{$\begin{array}{l}\text { Underlying disease } \\
\text { at admission }\end{array}$} & \multirow[b]{2}{*}{ Bacteremia } & \multirow[b]{2}{*}{ Outcome } & \multicolumn{2}{|c|}{ Treatment } \\
\hline & & & & & & & Active drugs & $\begin{array}{l}\text { Non active } \\
\text { drugs }\end{array}$ \\
\hline 1 & $\mathrm{~F}$ & 49 & $\mathrm{IAB}$ & Liver disease & Yes & Death & TG, AMK & \\
\hline 2 & M & 42 & $\mathrm{IAB}$ & Liver disease & No & Death & & \\
\hline 3 & M & 48 & $\mathrm{IAB}$ & Bariatric surgery & No & Survival & & COL \\
\hline 4 & M & 64 & CLABSI & ALL HSCT & Yes & Survival & TG, AMK & MER \\
\hline 5 & M & 73 & $\mathrm{IAB}$ & Colon cancer & No & Death & AMK & MER,TG \\
\hline 6 & $\mathrm{~F}$ & 34 & CLABSI & ALL HSCT & Yes & Death & AMK & \\
\hline 7 & M & 26 & $\mathrm{IAB}$ & $\begin{array}{l}\text { Kidney-pancreas } \\
\text { transplantation }\end{array}$ & No & Death & TG & MER,COL \\
\hline 8 & $\mathrm{~F}$ & 63 & CLABSI & Diabetic ketoacidosis & Yes & Survival & TG, AMK & MER \\
\hline 9 & M & 67 & other & Coronary heart disease & Yes & Death & $\mathrm{TG}$ & MER,COL \\
\hline 10 & $\mathrm{~F}$ & 23 & CLABSI & Liver disease & Yes & Survival & & MER,COL \\
\hline 11 & M & 36 & CLABSI & AML & Yes & Survival & $\mathrm{TG}$ & MER,COL \\
\hline 12 & M & 64 & $\mathrm{IAB}$ & Cholangio-carcinoma & No & Death & TG, AMK & IMI,COL \\
\hline 13 & $\mathrm{~F}$ & 20 & $\mathrm{IAB}$ & Perforative peritonitis & No & Death & & IMI,COL \\
\hline 14 & $\mathrm{~F}$ & 68 & CLABSI & $\begin{array}{l}\text { Chagasic megacolon } \\
\text { complications }\end{array}$ & Yes & Death & TG & MER,COL \\
\hline 15 & M & 51 & CLABSI & Burns & Yes & Death & TG,GEN & $\mathrm{COL}$ \\
\hline 16 & M & 59 & $\mathrm{IAB}$ & Liver disease & Yes & Death & TG, AMK & COL,CIP \\
\hline 17 & $\mathrm{~F}$ & 37 & $\mathrm{IAB}$ & $\begin{array}{l}\text { Kidney-pancreas } \\
\text { transplantation }\end{array}$ & No & Survival & $\mathrm{TG}$ & IMI \\
\hline 18 & M & 60 & $\mathrm{IAB}$ & Gastric adeno-carcinoma & No & Death & & TG,COL \\
\hline 19 & $\mathrm{~F}$ & 50 & $\mathrm{IAB}$ & Cholangio-carcinoma & No & Death & & \\
\hline 20 & $\mathrm{~F}$ & 51 & CLABSI & AML & Yes & Death & & MER,COL \\
\hline 21 & $\mathrm{~F}$ & 58 & CLABSI & Mesenteric ischemia & Yes & Death & TG, FOS & MER \\
\hline 22 & M & 49 & IAB & $\begin{array}{l}\text { Liver transplantation } \\
\text { complications }\end{array}$ & Yes & Survival & & IMI \\
\hline 23 & $\mathrm{~F}$ & 52 & CLABSI & $\begin{array}{l}\text { T cells non- Hodgkin } \\
\text { lymphoma }\end{array}$ & Yes & Survival & & IMI \\
\hline 24 & M & 60 & CLABSI & $\begin{array}{l}\text { Liver transplantation } \\
\text { complications }\end{array}$ & Yes & Survival & AMK & \\
\hline 25 & M & 60 & $\mathrm{IAB}$ & $\begin{array}{c}\text { Abdominal wall hernia repair } \\
\text { complications }\end{array}$ & Yes & Survival & & $\mathrm{COL}$ \\
\hline 26 & M & 28 & other & Polytrauma & No & Death & & \\
\hline 27 & $\mathrm{M}$ & 61 & $\mathrm{IAB}$ & $\begin{array}{l}\text { Liver transplantation } \\
\text { complications }\end{array}$ & No & Death & & COL \\
\hline 28 & M & 59 & $\mathrm{IAB}$ & $\begin{array}{l}\text { Liver transplantation } \\
\text { complications }\end{array}$ & Yes & Death & & SMX-TMP \\
\hline
\end{tabular}

Pt - patient; F - female; M - male; IAB - intra-abdominal infection; CLABSI - central line associated bloodstream infection; ALL - acute lymphoid leukemia; HSCT - hematopoietic stem cell transplantation; AML - acute myeloid leukemia; TG - tigecycline; AMK - amikacin; COL - colistin; MER - meropenem; IMI - imipenem; Fos - Fosfomycin; SMX-TMP - sulfamethoxazole-trimethoprim

to other sources) were $17(61 \%)$. The mean time elapsed from admission to infection diagnosis was 35 days (range 1 - 129), from infection to death 28 days (range 1-128) with a median of 15 days. The mean APACHE was 16 (5 - 36) and Charlson comorbidity index was $5(2-12)$. Fifteen patients (53\%) received active drugs to treat ColRKp infections based on the broth microdilution method, seven of them received two active drugs and eight received one active drug. Among these fifteen patients, twelve patients received additional non-active drugs associated to the active regimen. Other ten patients (35\%) received only non-active drugs in monotherapy or dual regimen. Three patients (10\%) 
did not receive any drug. Prescribed regimens are described in Table 1. The mean time elapsed from diagnosis (day when positive blood culture result was released ) to the first dose of active drug was 2.8 days ranging from 0 to 7 .

The distribution of the minimal inhibitory concentration of antimicrobials tested by the broth microdilution method for 26 isolates is presented in Table 2. Regarding carbapenemase-encoding genes, 26 isolates (93\%) had $b l a_{\mathrm{kpc},}$ and one of them was also positive also to $b l a_{\mathrm{NDM}-1}$ The genes $b l a_{\text {OXA-48 }}$ and $m c r-1$ were not identified. The dendrogram of the 26 isolates tested by PFGE revealed the presence of eight different clusters (Figure 1).

WGS was performed for six randomly selected ColRKP isolates. Four STs were prevalent (ST11, ST23, ST340, and ST437), three isolates were from ST11.

The analysis of resistance genes detected the presence of $b l a_{\mathrm{KPC}}-2$ in all 6 isolates, one of them co-harbouring the $b l a_{\mathrm{NDM}-1}$ gene. All the isolates sequences had ompK35 and отрK 36 genes, except for the isolate 4219 , which presented a disrupted ompK35 gene due to a frameshift.

Plasmid mediated colistin-resistance related to the presence of $m c r-1$ was not found. All 6 isolates presented chromosome non-synonymous mutations on genes related to colistin-resistance. Mutations on pmrA, arnB, $u d g$, and $y c i M$ were present in all six isolates; lpxM, and $m g r B$ mutations were also present in all but one isolate. All non-synonymous mutations found are described in Table 3. Other antimicrobial resistance-related genes fwere described in Table 4.

\section{DISCUSSION}

In December 2010, we identified the first isolate of K. pneumoniae presenting elevated inhibitory concentration (ColRKP) to colistin in blood. Since then, we have faced an increasing incidence of this agent causing healthcareassociated infection in our hospital, reaching $30 \%$ of all
K. pneumoniae carbapenem-resistant isolates (data not shown) in 2016. The emergence of polymyxin-resistant strains, especially to colistin (polymyxin E) has been identified in different countries ${ }^{15}$. In Italy, the emergence of colistin-resistant carbapenemase-producing $K$. pneumoniae has been reported since $2010^{16}$ and in an Italian nationwide cross-sectional survey in 2011, colistin resistance was found in $22.4 \%$ of CRKP isolates ${ }^{17}$.

We presented here 28 cases of bloodstream and/or sterile site infections that were well characterized in terms of molecular epidemiology and clonal relatedness. Severe comorbidities were associated to all cases. Fifteen patients received one or two active drugs, ten did not receive any active drug and three did not receive any antimicrobial drug for this infection. All of the treated patients received standard doses during treatment, unless an acute renal failure occurred.

Polymyxins are cationic peptides that exert their bactericidal effect by binding a peptide to the bacterial lipid A portion of lipopolysaccharide A (LPS A) that presents a negative charge in the outer membrane. Once it is bound, polymyxin displaces the cations $\mathrm{Mg}^{++}$and $\mathrm{Ca}^{++}$, disrupting the membrane integrity, leading to cell lysis ${ }^{18}$. A strategy used by Gram-negatives pathogens to overcome these drugs is to alter their LPS. More often, LPS modification takes place substituting the phosphate groups by 4-amino-4-deoxy-L-arabinose (L-Ara4N) which decreases the negative charge of LPS A reducing its binding to polymyxins ${ }^{7}$. Another mechanism that reduces the binding to the drug by altering the negative charge is the addition of phosphoethanolamine (PEtN). Chromosome mutations on the two-component transcriptional regulatory systems PmrAB and PhoPQ, or on the MgrB, leads to upregulation of modified LPS being associated to polymyxin resistance ${ }^{19-22}$. Less frequently is the expression of an efflux pump and capsule formation ${ }^{7}$. Cassu-Corsi et al. ${ }^{23}$ have recently reported two well characterized

Table 2 - Distribution of the minimal inhibitory concentration of antimicrobials tested by the broth microdilution method for the 26 isolates of Klebsiella pneumoniae.

\begin{tabular}{lcccccccc}
\hline Antimicrobial & breakpoint & $\mathrm{N}$ & $\% \mathrm{R}$ & $\% \mathrm{l}$ & $\% \mathrm{~S}$ & MIC50 & MIC90 & MIC variation \\
\hline Imipenem & $\mathrm{S} \leq 1 \mathrm{R} \geq 4$ & 26 & 85.7 & 10.7 & 3.6 & 16 & 16 & $1-16$ \\
Meropenem & $\mathrm{S} \leq 1 \mathrm{R} \geq 4$ & 26 & 92.9 & 0 & 7.1 & 16 & 16 & $1-16$ \\
Amikacin & $\mathrm{S} \leq 16 \mathrm{R} \geq 64$ & 26 & 17.9 & 3.6 & 78.6 & 4 & 64 & $2-64$ \\
Gentamicin & $\mathrm{S} \leq 4 \mathrm{R} \geq 16$ & 26 & 78.6 & 0 & 21.4 & 16 & 16 & $1-16$ \\
Ciprofloxacin & $\mathrm{S} \leq 1 \mathrm{R} \geq 4$ & 26 & 96.4 & 0 & 3.6 & 4 & 4 & $1-4$ \\
Colistin & $\mathrm{S} \leq 2 \mathrm{R} \geq 8$ & 26 & 96.4 & 3.6 & 0 & 16 & 16 & $4-16$ \\
Tigecycline & $\mathrm{S} \leq 2 \mathrm{R} \geq 8$ & 26 & 10.7 & 7.1 & 82.1 & 2 & 8 & $0.5-8$ \\
\hline
\end{tabular}

MIC - minimal inhibitory concentration; R - resistant; I - intermediate; S - susceptible 
Boszczowski et al.

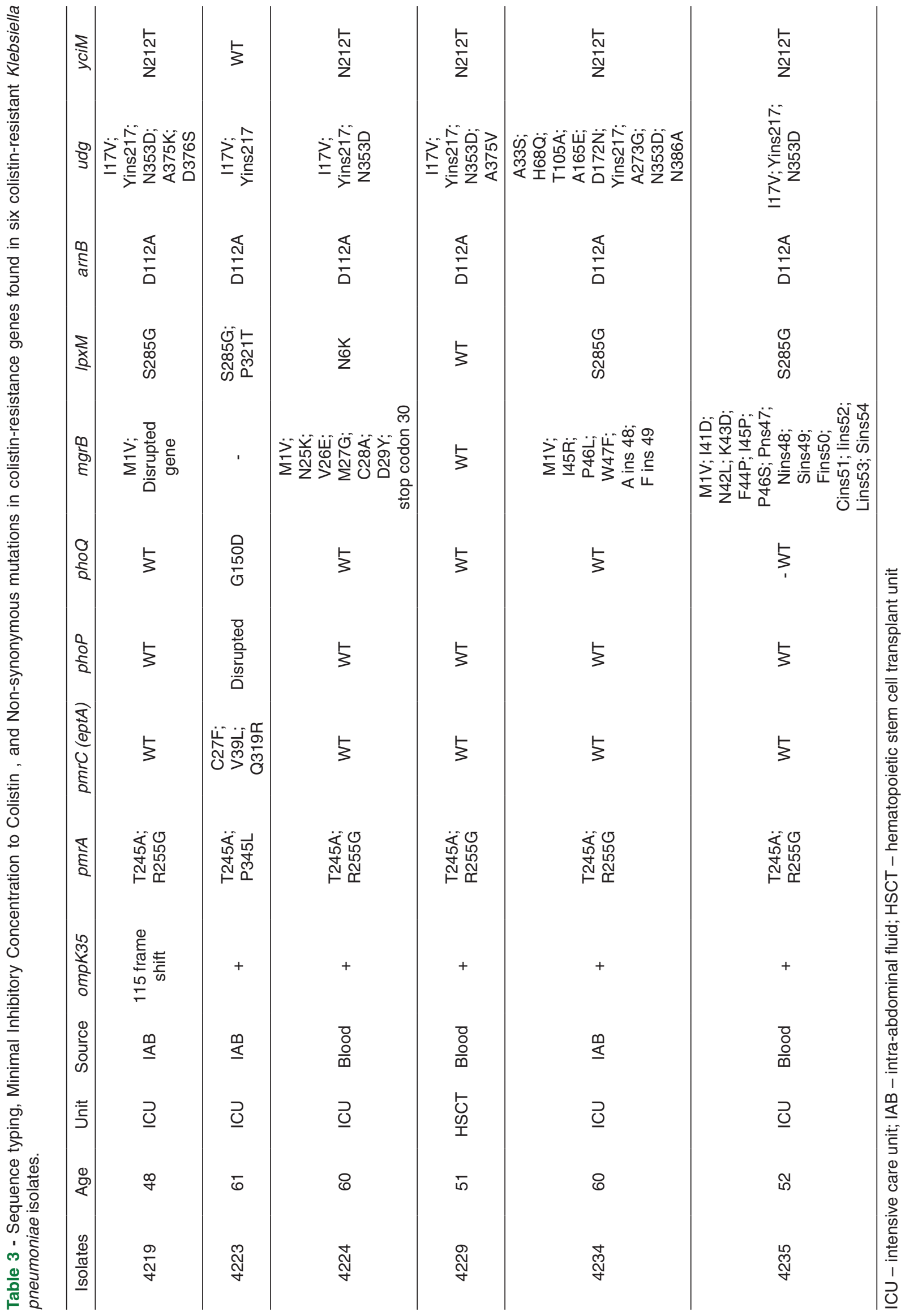


Table 4 - Whole genome sequencing of six isolates of colistin-resistant Klebsiella pneumoniae.

\begin{tabular}{|c|c|c|c|c|c|c|c|c|}
\hline Isolates & MLST & Aminoglycoside & Beta-lactam & Fluoroquinolone & Fosfomycin & Chloramphenicol & Sulphonamide & Trimethoprim \\
\hline 4219 & 11 & $\begin{array}{c}\text { aadA2; } \\
\text { aacA4; } \\
\text { aph(3')-la; } \\
\operatorname{aac(3)-lla}\end{array}$ & $\begin{array}{c}\text { blaKPC-2; } \\
\text { blaSHV-11; } \\
\text { blaTEM-1B; } \\
\text { blaOXA-2 }\end{array}$ & $\begin{array}{c}o q x A ; \\
o q x B ; a \\
a c\left(6^{\prime}\right) I b-c r\end{array}$ & fos $A$ & - & sul1 & dfrA12 \\
\hline 4223 & 23 & $\begin{array}{c}\text { aac(3)-lia; } \\
\text { aacA4 }\end{array}$ & $\begin{array}{c}\text { blaKPC-2; } \\
\text { blaOXA-2; } \\
\text { blaOXA-9; } \\
\text { blaCTX-M-2; } \\
\text { blaTEM-1A; } \\
\text { blaSHV-3 }\end{array}$ & $\begin{array}{c}\text { oqxA; } \\
\text { oqxB; } \\
\operatorname{aac}\left(6^{\prime}\right) I b-c r\end{array}$ & fos $A$ & - & sul1 & - \\
\hline 4224 & 11 & $\begin{array}{l}\operatorname{aac}\left(6^{\prime}\right)-l q ; \\
\text { aacA4; } \\
\text { aph(3')-la; } \\
\text { aac(3)-lia; } \\
\text { aadA1 }\end{array}$ & $\begin{array}{c}\text { blaKPC-2; } \\
\text { blaSHV-11; } \\
\text { blaOXA-2; } \\
\text { blaTEM-1B; } \\
\text { blaCTX-M-2 }\end{array}$ & $\begin{array}{c}\operatorname{aac}\left(6^{\prime}\right) l b-c r \\
\text { oqxA; } \\
\text { oqxB }\end{array}$ & fos $A$ & $\begin{array}{l}\text { cmIA1; } \\
\text { catA1; } \\
\text { catA2 }\end{array}$ & sul1; sul2 & dfrA15 \\
\hline 4229 & 11 & $\begin{array}{c}\operatorname{aad} A 2 ; \\
\operatorname{aacA4;} \\
\operatorname{aac}(3)-l i a\end{array}$ & $\begin{array}{c}\text { blaCTX-M-2; } \\
\text { blaSHV-11; } \\
\text { blaTEM-1B; } \\
\text { blaOXA-2 }\end{array}$ & $a a c\left(6^{\prime}\right) l b-c r$ & fos $A$ & catA1 & sul1 & dfrA12 \\
\hline 4234 & 340 & $\begin{array}{c}a p h\left(3^{\prime}\right)-l a ; \\
\text { aph(3')-Via; } \\
\text { aadA2 }\end{array}$ & $\begin{array}{c}\text { blaSHV-11; } \\
\text { blaCTX- } \\
\text { M-15; } \\
\text { blaKPC-2; } \\
\text { blaNDM }\end{array}$ & oqxA; oqxB & fosA & - & sul1 & $\begin{array}{l}\text { dfrA12; } \\
\text { dfrA14 }\end{array}$ \\
\hline 4235 & 437 & $\begin{array}{l}\text { aph(3')-la; } \\
\text { aadA2 }\end{array}$ & $\begin{array}{l}\text { blaKPC-2; } \\
\text { blaSHV-11; }\end{array}$ & oq $x A ;$ oqxB & fos $A$ & - & sul1 & dfrA30 \\
\hline
\end{tabular}

K. pneumoniae strains expressing loss of porins ompk35 and ompk36 associated with other mechanisms.

We identified 26 strains harboring $b l a_{\mathrm{kpc}}$ gene. The two remaining isolates tested negative for $b l a_{\mathrm{KPC}}, b l a_{\text {OXA-48 }}$ and $b l a_{\mathrm{NDM}}$ polymerase chain reaction. In six isolates, WGS detected several mutations in important genes related to LPS modification, such as pmrA, $\operatorname{mgrB}, \operatorname{lp} x M$, arnB, $u d g$ and yciM. The pmrAT245A and R255G; $a r n B$ D112A; and $u d g \mathrm{I} 17 \mathrm{~V}$ and Yins 217 mutations were present in all six isolates; the $y c i M \mathrm{~N} 212 \mathrm{~T}$ and $l p x M \mathrm{~S} 285 \mathrm{G}$ mutations were also present in 5 and 4 isolates, respectively. The role of these mutations is not yet clear, but their simultaneous presence in all those genes that are already known to be involved with colistin-resistance in the colRKP isolates suggest that they may also lead to polymyxinresistance ${ }^{20-24}$. Four different MLST were identified, and although there were three isolates from MLST 11, they did not share the same mutations, which suggest that they were not from a clonal lineage, corroborating the clustering analysis results. These results in addition to the fact that we did not find the plasmid $m c r-1$ indicate that colistin-resistance is more likely due to selective pressure by the use of colistin, rather than a plasmid or clonal spread amongst our isolates.

We did not find the presence of gene $m c r-1$ among these six isolates submitted to WGS, although we had identified in our hospital two isolates in 2016 (data not shown). Gene mcr-1 has been described as an important mechanism of colistin-resistance. Liu et al. ${ }^{25}$ reported a plasmidial $m c r-1$ gene in $E$. coli identified in raw meat, animals and humans conferring elevated MICs $(8 \mu \mathrm{g} / \mathrm{ml})$ to colistin. Plasmidmediated resistance has epidemiological implications due to a facilitated way of spread, including $K$. pneumoniae, as seen previously with ESBL and $\mathrm{KPC}^{26}$.

Moreover, isolates of $E$. coli and S. enterica with elevated MIC to colistin were found in pigs, in Brazil ${ }^{27}$. Although interspecies transmission is not completely understood, the use of polymyxins by veterinarians is a colistin-resistance growth promoter and their consequences to human health are of great concern. 
We have seen in our institution, the emergence of carbapenem non-susceptible Enterobacteriaceae, increasing from 0.01 to 1.6/1000 patient-day in 2007 and 2016, respectively. Most of them (70\%) harbor carbapenemaseproducing $K$. pneumoniae (data not shown). As a result of this scenario, colistin has been used as a key drug to treat patients affected by this pathogen, often associated with other drugs especially, aminoglycosides, tigecycline, fosfomycin (study protocol) ${ }^{28}$ and meropenem, regardless of susceptibility ${ }^{3}$. Thus, the extensive use of polymyxins due to increasing carbapenem-resistant pathogens may have exerted a selective pressure leading to the emergence of resistant strains. Twelve patients and one patient were exposed to colistin or polymyxin B, respectively, prior to the occurrence of ColRKP infection in this cohort. The rate of polymyxins use has been on average $27.7 \mathrm{DDD} / 1000$ patients-day in our hospital in the last ten years (2007-2016) which is positioned in percentile 75 among 321 intensive care units in Sao Paulo State (Southeastern Brazil), the region in which we are located ${ }^{29}$. In our series, the fact that 28 isolates were distributed in eight clusters reinforced the possibility of selective pressure. Although efforts to prevent cross transmission have been employed, the judicious use of polymyxins is a primary and urgent need. Moreover, the epidemiology of naturally polymyxin-resistant pathogens, such as Proteus, Providencia, Morganella and Serratia might change in the near future due the increasing use of these drugg ${ }^{30}$.

Our study is limited by the small number of strains, especially of those studied by WGS. Although we identified several mutations in genes previously related to colistinresistance we cannot assure that they were directly involved in these cases. Further transcriptomics studies are needed to verify if these mutations led to LPS alterations.

Colistin-resistance in carbapenem resistant $K$. pneumoniae is of great concern as few therapeutic options if any, are left. Strict control measures that prevent dissemination, as well as the judicious use of polymyxins are important measures until new drugs or alternative therapeutic approaches are available.

\section{REFERENCES}

1. Monteiro J, Santos AF, Asensi MD, Peirano G, Gales AC. First report of KPC-2-producing Klebsiella pneumoniae strains in Brazil. Antimicrob Agents Chemother. 2009;53:333-4.

2. Pavez M, Mamizuka, Lincopan N. Early dissemination of KPC-2producing Klebsiella pneumoniae strains in Brazil. Antimicrob Agents Chemother. 2009;53:2702

3. Oliveira MS, Assis DB, Freire MP, Boas do Prado GV, Machado AS, Abdala E, et al. Treatment of KPC-producing
Enterobacteriaceae: suboptimal efficacy of polymyxins. Clin Microbiol Infect. 2015;21:179.e1-7.

4. Gomez-Simmonds A, Nelson B, Eiras DP, Loo A, Jenkins SG, Whittier S, et al. Combination regimens for treatment of carbapenem-resistant Klebsiella pneumoniae bloodstream infections. Antimicrob Agents Chemother. 2016;60:3601-7.

5. Sampaio JL, Gales AC. Antimicrobial resistance in Enterobacteriaceae in Brazil: focus on $\beta$-lactams and polymyxins. Braz J Microbiol. 2016;47 Suppl 1:31-7

6. Rossi F, Girardello R, Cury AP, Di Gioia TS, Almeida Junior JN, Duarte AJ. Emergence of colistin resistance in the largest university hospital complex of São Paulo, Brazil, over five years. Braz J Infect Dis. 2017;21:98-101.

7. Olaitan AO, Morand S, Rolain JM. Mechanisms of polymyxin resistance: acquired and intrinsic resistance in bacteria. Front Microbiol. 2014;5:643.

8. Clinical and Laboratory Standards Institute. Performance standards for antimicrobial susceptibility testing; twenty-fourth informational supplement. Wayne: CLSI; 2014.

9. Zhang Z, Chen M, Yu Y, Pan S, Liu Y. Antimicrobial susceptibility among Gram-positive and Gram-negative blood-borne pathogens collected between 2012-2016 as part of the Tigecycline Evaluation and Surveillance Trial. Antimicrob Resist Infect Control. 2018;7:152.

10. Antonelli A, Arena F, Giani T, Colavecchio OL, Valeva SV, Paule $\mathrm{S}$, et al. Performance of the BD MAX ${ }^{\mathrm{TM}}$ instrument with Check-Direct CPE real-time PCR for the detection of carbapenemase genes from rectal swabs, in a setting with endemic dissemination of carbapenemase-producing Enterobacteriaceae. Diagn Microbiol Infect Dis. 2016;86:30-4.

11. National Center for Biotechnology Information. [cited 2019 Apr 26]. Available from: http://www.ncbi.nlm.nih.gov

12. Seemann T. Prokka: rapid prokaryotic genome annotation. Bioinformatics. 2014;30:2068-9.

13. Larsen MV, Cosentino S, Rasmussen S, Friis C, Hasman H, Marvig RL, et al. Multilocus sequence typing of total-genomesequenced bacteria. J Clin Microbiol. 2012;50:1355-61.

14. Zankari E, Hasman H, Cosentino S, Vestergaard M, Rasmussen $\mathrm{S}$, Lund O, Identification of acquired antimicrobial resistance genes. J Antimicrob Chemother. 2012;67:2640-4.

15. Elemam A, Rahimian J, Doymaz M. In vitro evaluation of antibiotic synergy for polymyxin B-resistant carbapenemaseproducing Klebsiella pneumoniae. J Clin Microbiol. 2010;48:3558-62.

16. Mezzatesta ML, Gona F, Caio C, Petrolito V, Sciortino D, Sciacca A, et al. Outbreak of KPC-3-producing, and colistin-resistant, Klebsiella pneumoniae infections in two Sicilian hospitals. Clin Microbiol Infect. 2011;17:1444-7.

17. Giani T, Pini B, Arena F, Conte V, Bracco S, Migliavacca R, et al. Epidemic diffusion of KPC carbapenemase-producing Klebsiella pneumoniae in Italy: results of the first countrywide 
survey, 15 May to 30 June 2011. Euro Surveill. 2013;18:20489.

18. Falagas ME, Kasiakou SK. Colistin: the revival of polymyxins for the management of multidrug-resistant gram-negative bacterial infections. Clin Infect Dis. 2005;40:1333-41.

19. Cannatelli A, D’Andrea MM, Giani T, Di Pilato V, Arena F, Ambretti S, et al. In vivo emergence of colistin resistance in Klebsiella pneumoniae producing KPC-type carbapenemases mediated by insertional inactivation of the PhoQ/PhoPmgrB regulator. Antimicrob Agents Chemother. 2013;57:5521-6.

20. Cannatelli A, Pilato VD, Giani T, Arena F, Ambretti S, Gaibani P, et al. In vivo evolution to colistin resistance by PmrB sensor kinase mutation in KPC-producing Klebsiella pneumoniae associated with low-dosage colistin treatment. Antimicrob Agents Chemother. 2014;58:4399-403.

21. Jayol A, Poirel L, Brink A, Villegas MV, Yilmaz M, Nordmann P.

Resistance to colistin associated to a single amino acid change in protein PmrB among Klebsiella pneumoniae of worldwide origin. Antimicrob Agents Chemother. 2014;58:4762-6.

22. Kim SY, Choi HJ, Ko KS. Differential expression of twocomponent systems, pmrAB and phoPQ, with different growth phases of Klebsiella pneumoniae in the presence or absence of colistin. Curr Microbiol. 2014;69:37-41.

23. Cassu-Corsi D, Martins WM, Scheffer MC, Cayô R, Gales AC. Misidentification of pan drug-resistant Klebsiella pneumoniae clinical isolates as a metallo- $\beta$-lactamase producers by the EDTA/DDTS test. Braz J Infect Dis. 2015;19:102-4.

24. Maio Carrilho CM, Gaudereto JJ, Martins RC, Castro Lima VA, Oliveira LM, Urbano MR, et al. Colistin-resistant Enterobacteriaceae infections: clinical and molecular characterization and analysis of in vitro synergy. Diagn Microbiol Infect Dis. 2017;87:253-7.
25. Liu YY, Wang Y, Walsh TR, Yi LX, Zhang R, Spencer J, et al. Emergence of plasmid-mediated colistin resistance mechanism MCR-1 in animals and human beings in China: a microbiological and molecular biological study. Lancet Infect Dis. 2016;16:161-8.

26. Caneiras C, Calisto F, Silva GJ, Lito L, Melo-Cristino J, Duarte A. First description of colistin and tigecycline-resistant Acinetobacter baumannii producing KPC-3 carbapenemase in Portugal. Antibiotics (Basel). 2018;7:E96.

27. Morales AS, Fragoso de Araújo J, Moura Gomes VT, Reis Costa AT, Prazeres Rodrigues D, Porfida Ferreira TS, et al. Colistin resistance in Escherichia coli and Salmonella entérica strains isolated from swine in Brazil. ScientificWorldJournal. 2012;2012:109795.

28. Perdigão Neto LV, Oliveira MS, Martins RC, Marchi AP, Gaudereto JJ, Costa LA, et al. Fosfomycin in severe infections due to genetically distinct pan-drug-resistant Gram-negative microorganisms: synergy with meropenem. J Antimicrob Chemother. 2019;74:177-81.

29. São Paulo. Secretaria da Saúde. Sistema de vigilância epidemiológica. [cited 2019 Apr 26]. Available from: http://www.saude.sp.gov.br/cve-centro-de-vigilanciaepidemiologica-prof.-alexandre-vranjac/areas-de-vigilancia/ infeccao-hospitalar/sistema-de-vigilancia-epidemiologica

30. Samonis G, Korbila IP, Maraki S, Michailidou I, Vardakas KZ, Kofteridis D, et al. Trends of isolation of intrinsically resistant to colistin Enterobacteriaceae and association with colistin use in a tertiary hospital. Eur J Clin Microbiol Infect Dis. 2014;33:1505-10 